\title{
تحليل النظرية التعلم على مستوى الدراسة
}

Dibi Afriansyah, M.Pd

Dosen Bahasa Arab IAIN Bengkulu

E-mail: debyafriansyah8@gmail.com

$$
\text { لكلمات المفتاحية:تحليل، نظرية التعلم، مستوى البحثلث الدراسة }
$$
إنما العملية التعليمية مجموعة منظمة ومنسقة من الأنشطة و الإجر اءات التي تهدف الته التهات

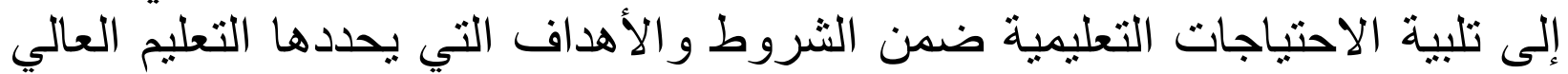
في الدولة، حيث ترتكز العملية التعليمية على المبادئ الأساسية؛ ومنها: الديمقر اطية،

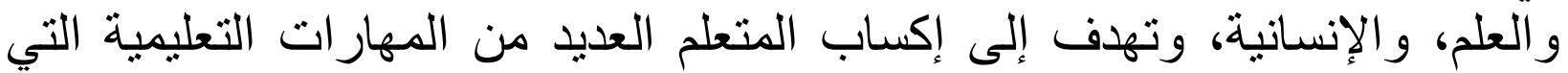
تجعل من شخصيته أكثر قوة و إتزان، وتساهم في إتاحة فرص صل العمل أمامهه.ولتحفيق

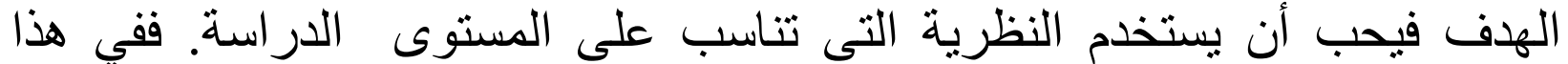

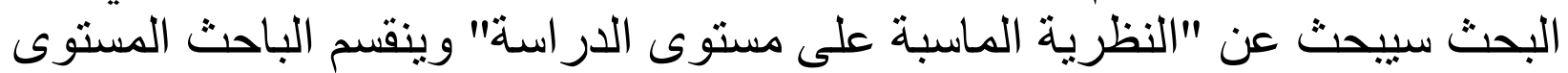

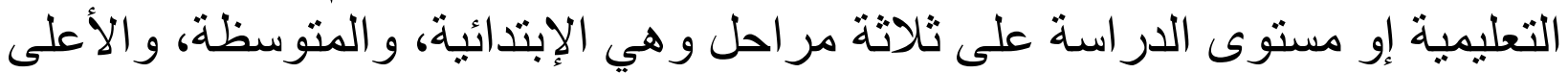
وفى كل مرحلة تتكون عل مر احل أيضا وهي الأدنى و الأوسط و الأعلى.

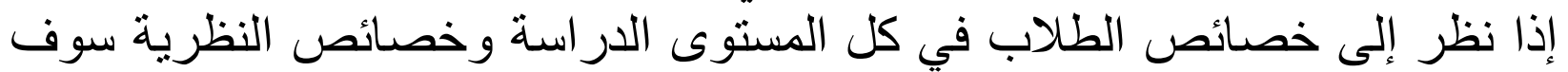
يوجد علاقة بينهما، فأنشطة تعلم الطلاب في كل المرحلة تناسب بأنشطة تطبيق النظرية. فالنظرية السلوكية تناسب أن تستخدم في المرحلة الإبتطائية لأن النظرية السلوكية يشتمل على المثير، التعزيز، و العقاب، وهذا الثناثة تناسب على على عملية

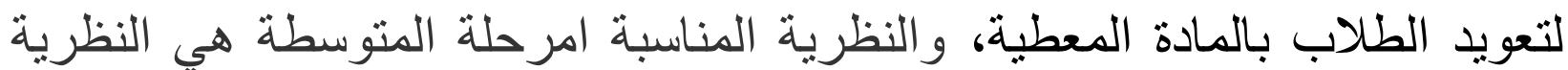

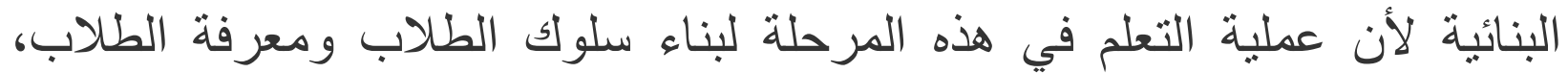
النظرية المناسبة بمرحلة الأعلى هي النظرية المعرفية لأن كثير من العمليات

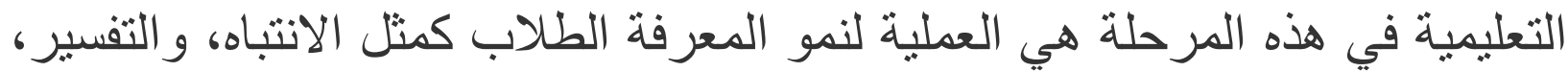
و التركيب، و التخزين ز التذكر، و الاستر جاع و اكتشاف المعرفة الجديدة. 


\section{مقدمة}

تعتبر العملية التعليمية مجموعة منظمة ومنسقة من الأنشطة والإجراءات

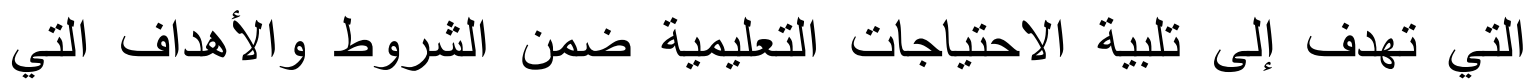
يحددها التعليم العالي في الدولة، حيث ترتكز العملية التعليمية على المبادئ

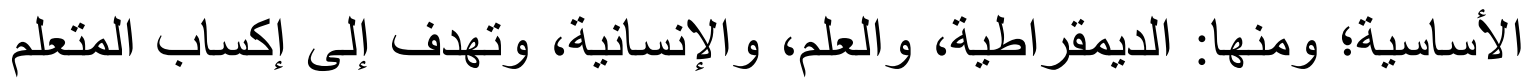

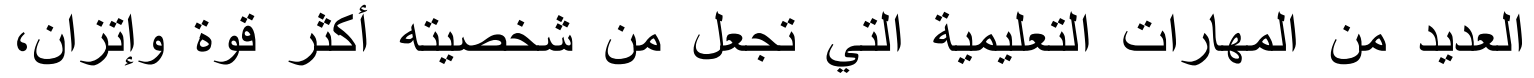
وتساهم في إتاحة فرص العمل أمامه. 1

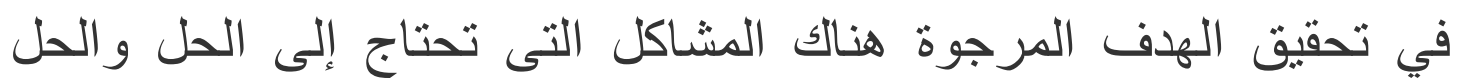
المقصودة النظرية التى تتاسب على المستوى التعليمية، ومعرفة النظرية

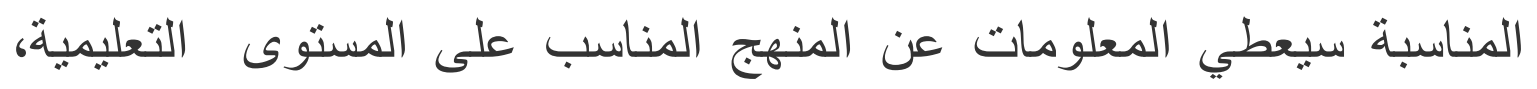

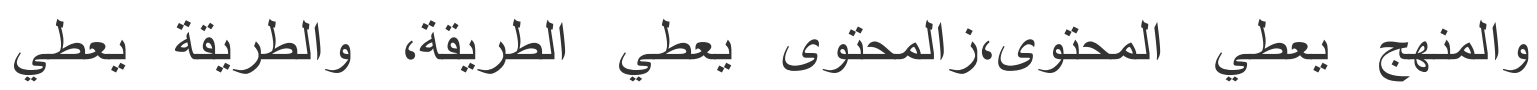

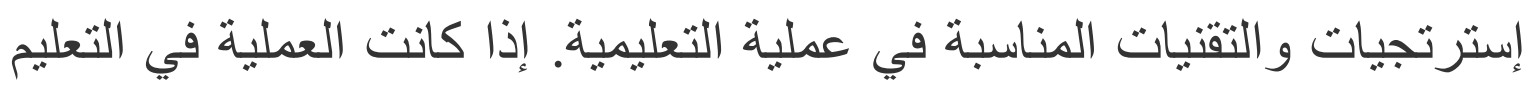

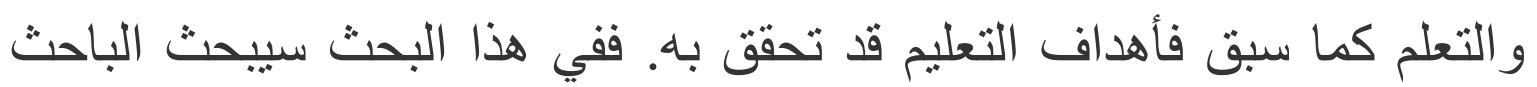

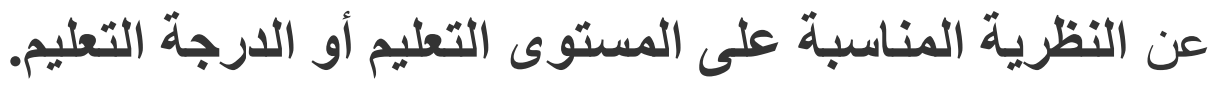

\section{منهج البحث}

يهدف هذا البحث إلى تقسيم النظرية التعلم على المستوى التعليمية. و واستخدم الباحث في هذا البحث منهج البحث المكتبي وسيتم تحليلها بشكل حاسم الفئ وعميق من خلال تتليث البيانات؛ تخفيض البيانات وعرض البيات البيانات واستخلاص النتائج.

\section{البحث}

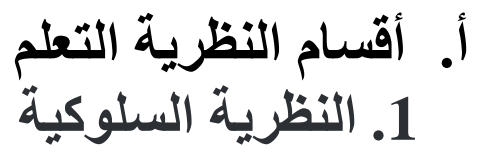

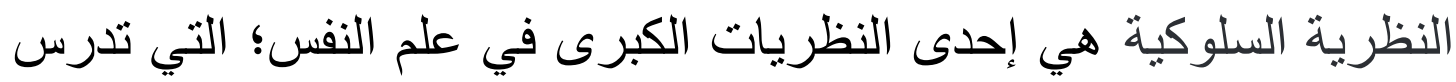

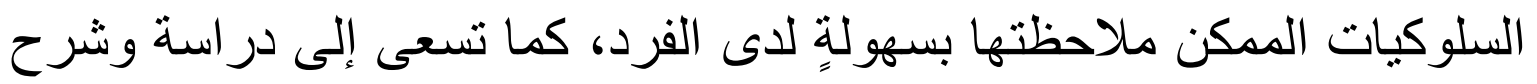
السلوك البشري، من خلال تحليل الظروف التي عاثها الفرد، والنتائج المترنبة التردية

${ }^{1}$ Features of the Educational Process", www.nubip.edu.ua,Retrieved 5-10-2018. Edited 
عليها في بيئته، و الخبرة المُكتسبة من تجاربه السابقة؛ والتي أدت إلى ظهور

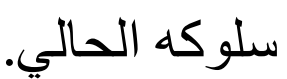
ولم تتبنَّ النظرية السلوكية فكرة وجود دورٍ للوعي في سلوك الفرد،

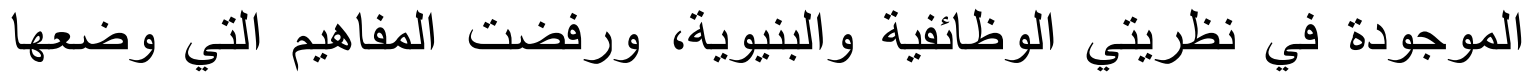

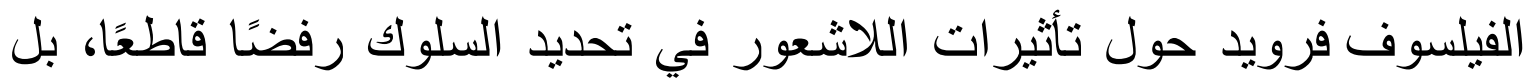

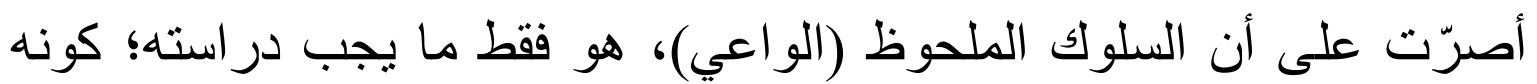

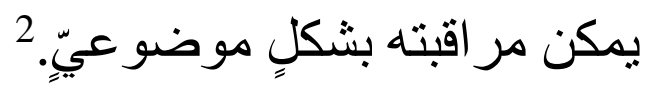

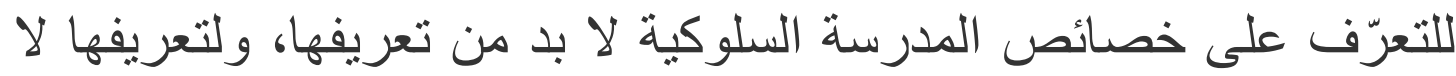

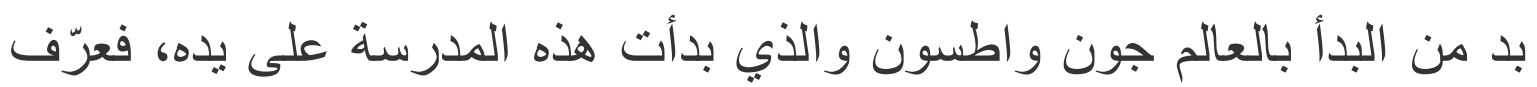

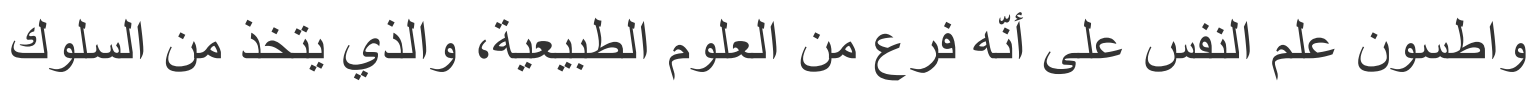

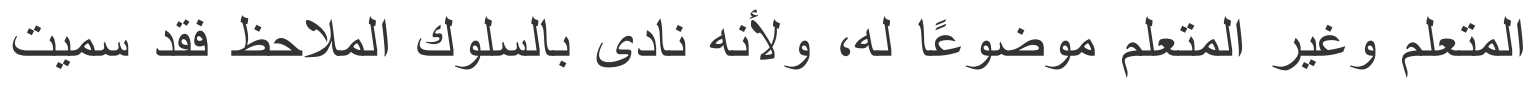

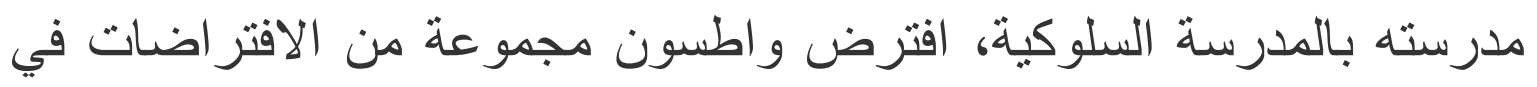
علم النفس، أهمها أن السلوك هو الملوكة عبارة عن نظام متعلم حيث تؤكد المدرسة

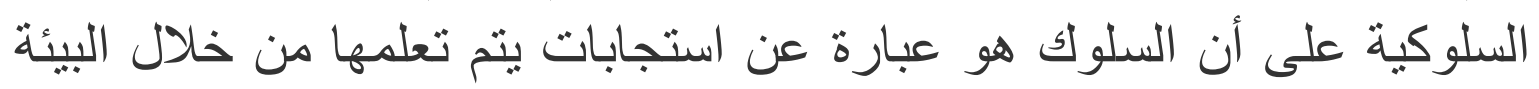

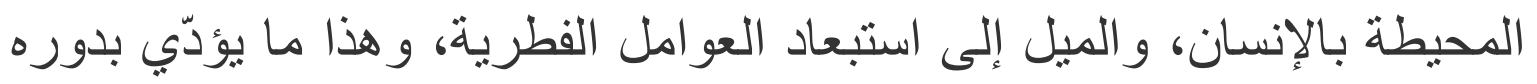

$$
\text { إلى الرقي بالإنسان ليتعلمج3. }
$$

\section{التطبيقات التربوية للنظرية السلوكية}

من أهم التطبيقات المهمة للنظرية السلوكية والتي يمكن للمعلمين تعلمها تلهيها

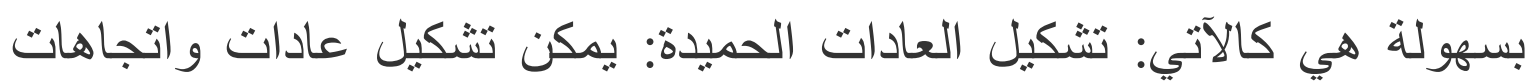

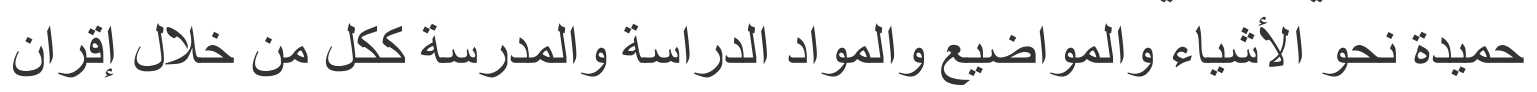

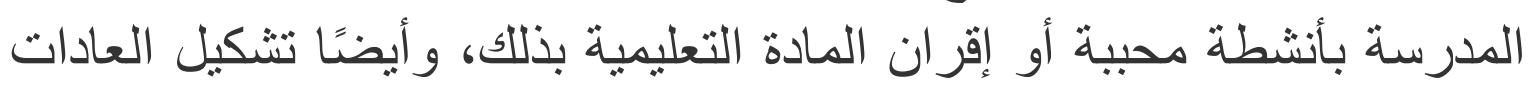

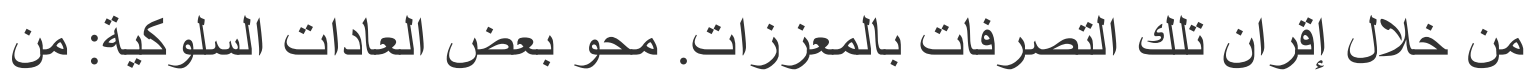

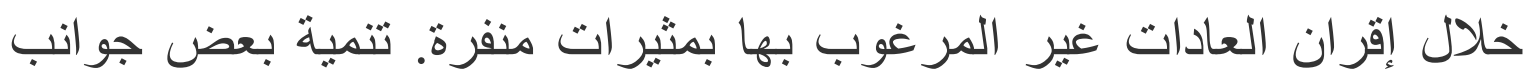

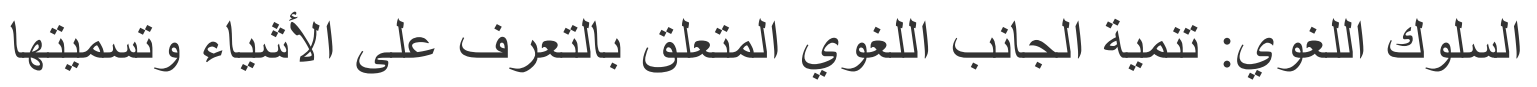

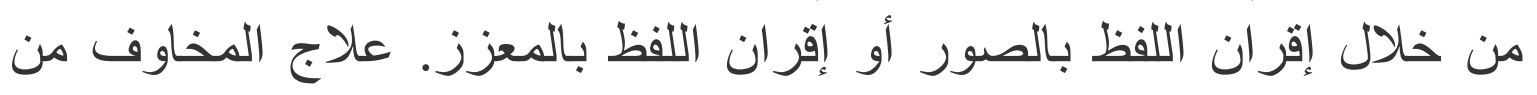

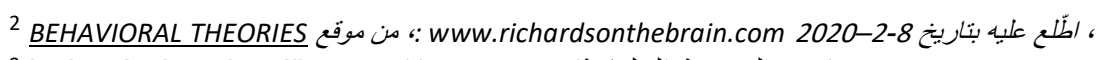

3 behaviorism.html",https://sotor.com/خصائص-المدرسة-السلوكية2020
} 
المدرسة: ويتم ذلك من خلال إز الة الر ابطة بين المثير المخيف و المدرسة، ويتم

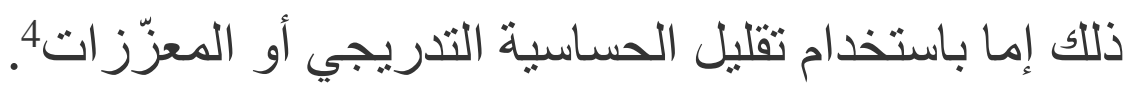

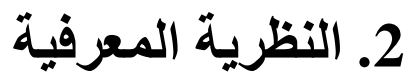

ترفض النظرية المعرفية أن التعلم هو نتيجة المؤثرات خارجية فقط ويسخر

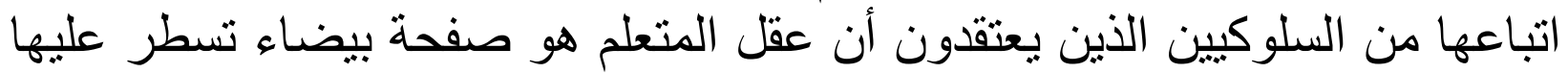

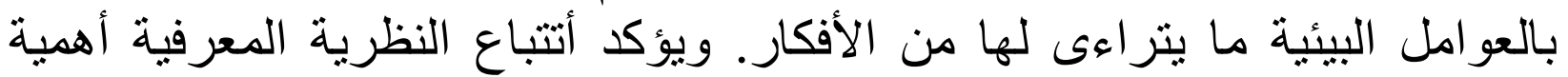

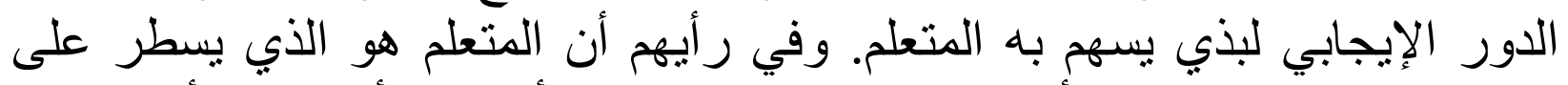

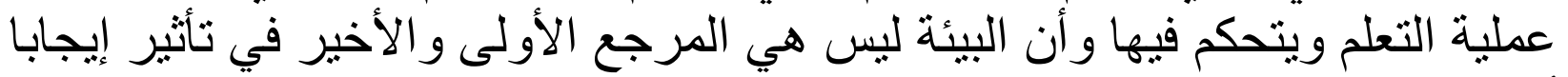

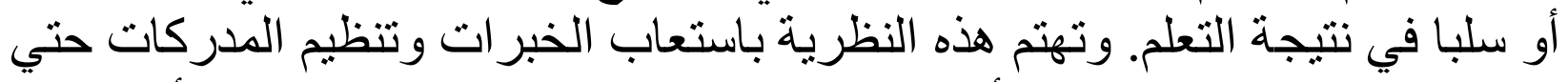

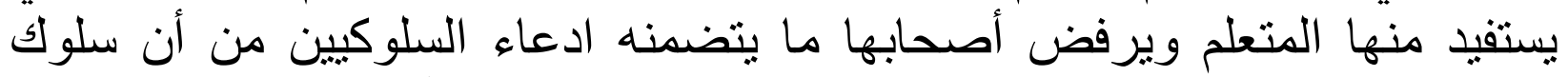

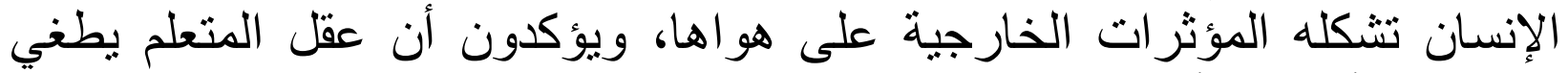

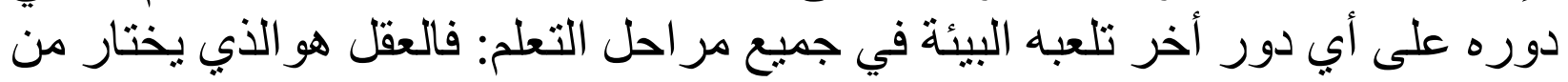

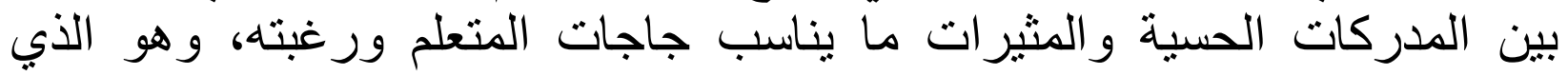

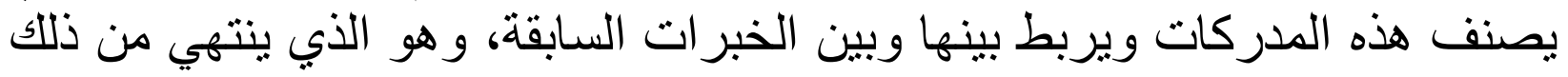

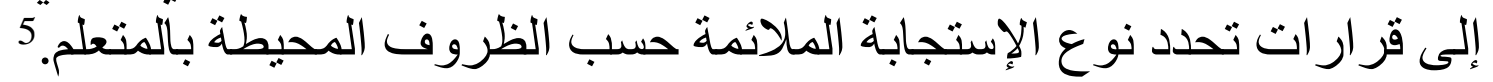

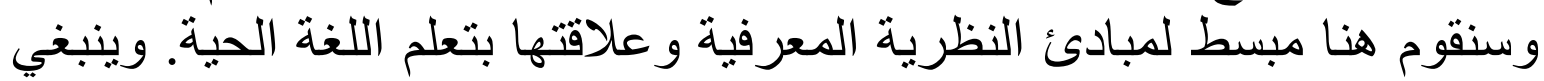

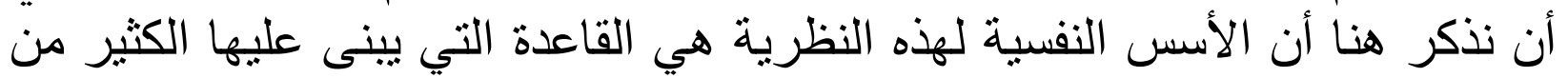

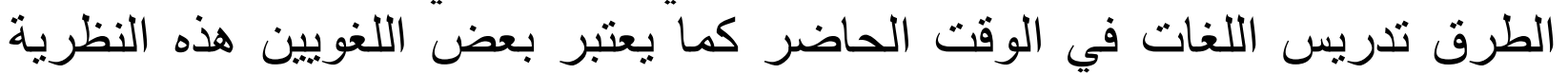

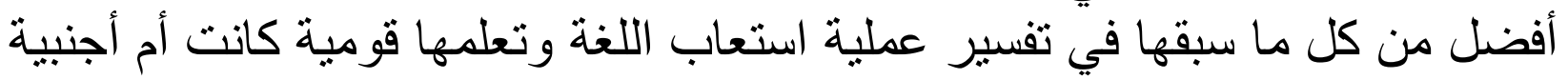

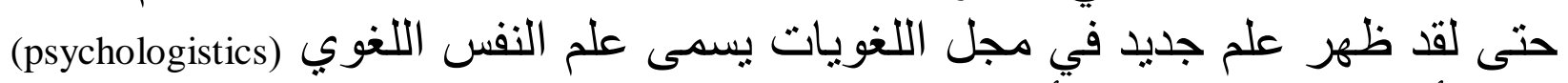

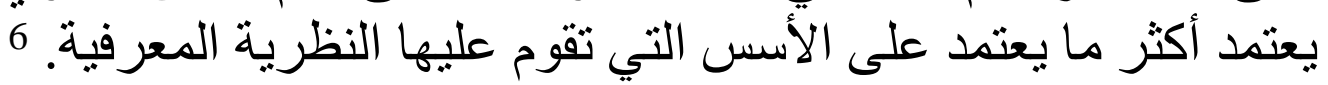

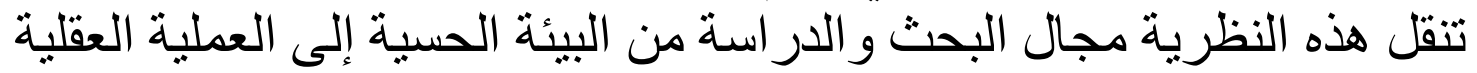

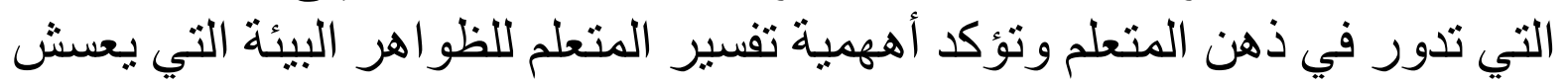

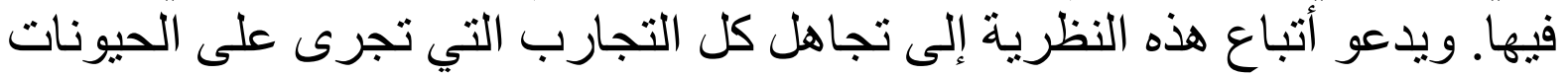

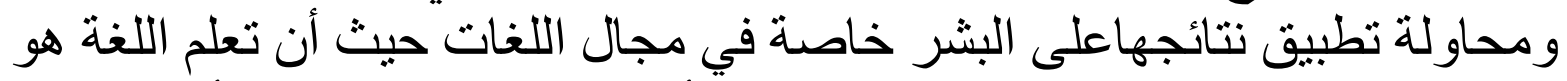

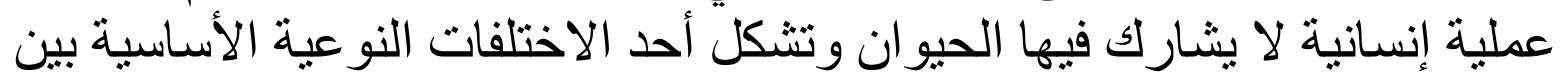

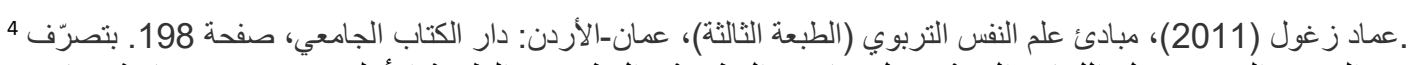
5 صلاح عبد الحجيد العربي، تعلم اللغات الحية وتعليهها بين النظرية والتطبيق، الطبعة الأولى، (بيروت: ساحة رياض النياض

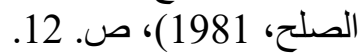
6 صلاح عبد الحجيد العربي، تعلم اللغات الحبة وتعليها بين النظرية والتطبيق، الطبعة الأولى، (بيروت: ساحة رياض الصلح، 1981)، ص. ص. 13 
قدرات الحيو ان والإنسان. ومن غير منطقي إذا أن نطبق عليها نتائج مبنية على السلوك الحيو اني وحده. 3. النظرية البنائية

إن الأساس الإنشائي لأي هيكل جديد من الممكن تحقيقه من خلال النضج النيات

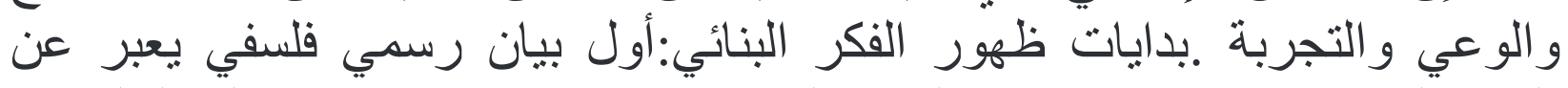
الفكر البنائي صدر في بدايات القرن الثنامن عشر (1710م) في مقولة النياني الفيلسوف

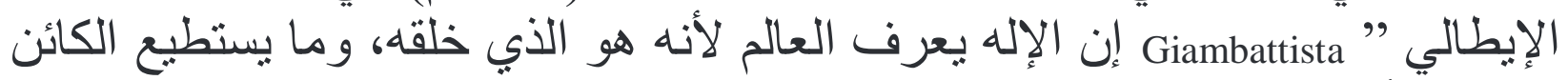

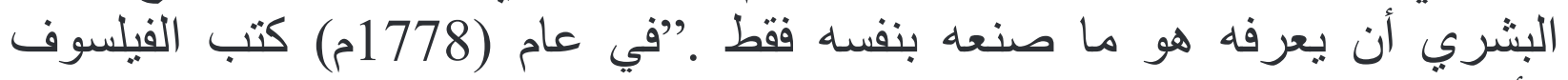

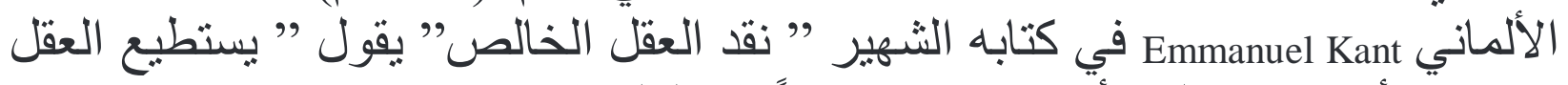
الإنساني أن يفهم فقط ما أنتجه هو نفسه وفقًا لخططه الخاصة بـاه.

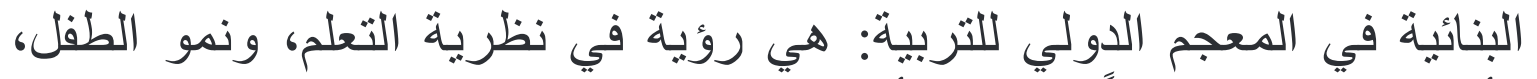

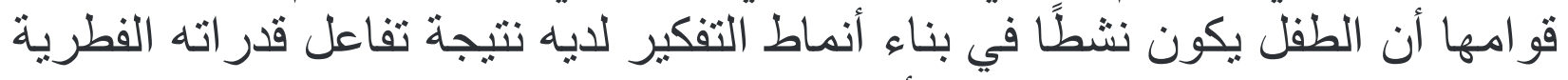

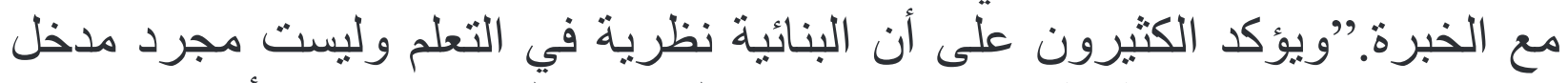

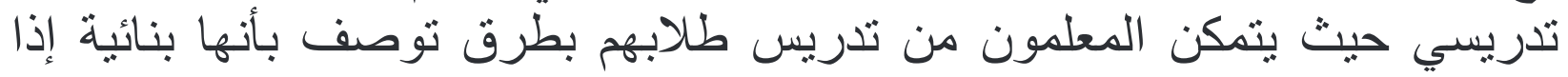

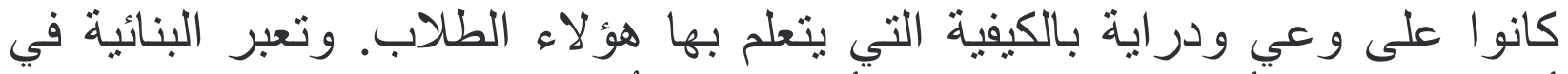

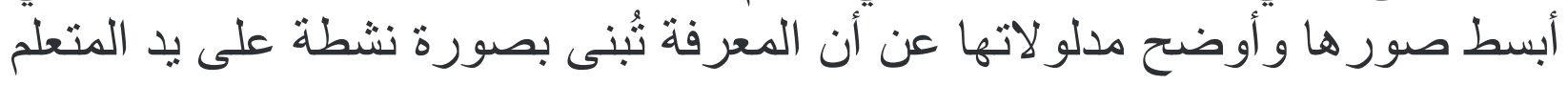
و لا يستقبلها بصورة سلبية من البيئة.

1) خصائص التعلم من منظور البنائية

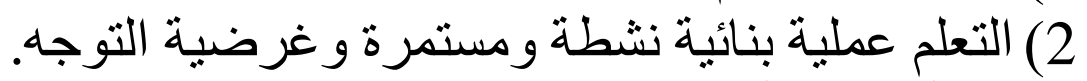

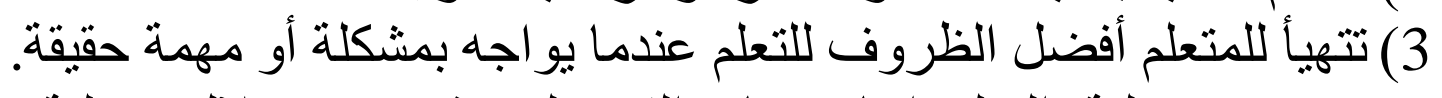

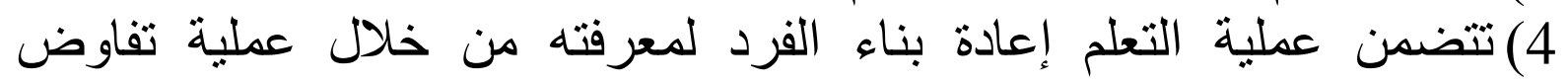
اجتماعي مع الآخرين.

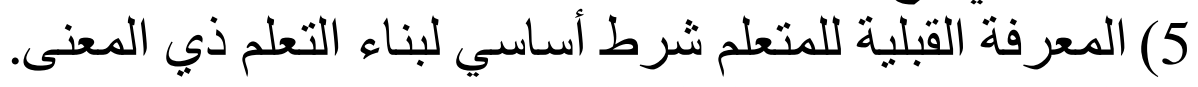

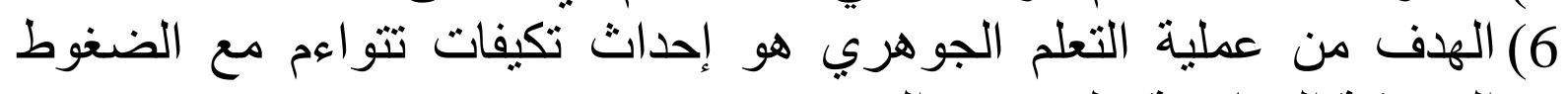
المعرفية الممارسة على خبرة الفئ الفردي.

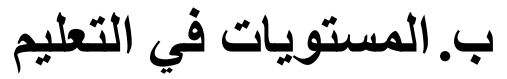

7 صلاح عبد الحجيد العربي، تعلم اللغات الحبة وتعلبمها بين النظرية والتطبيق، ص. 13 
كانت المستويات في التعليم بإندونيسيا قد ذكر في قانون الدولي إندونيسيا في السنة

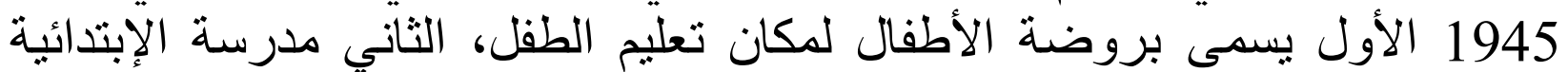

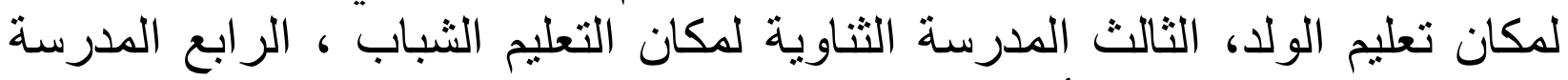

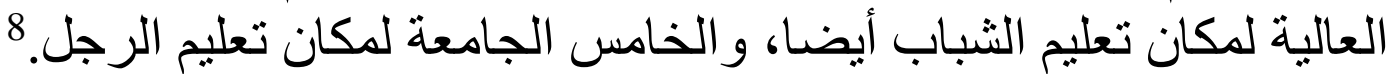

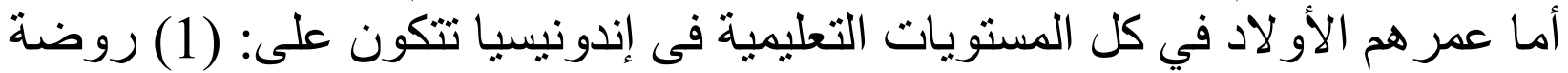

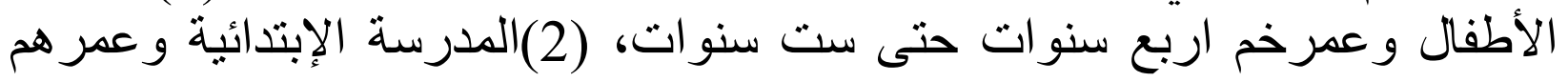

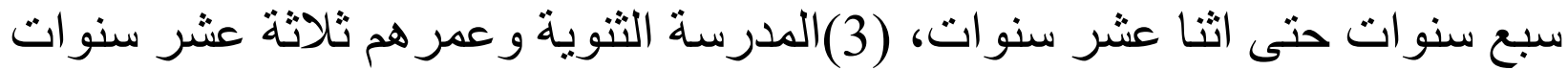

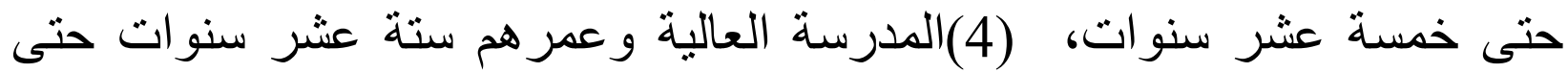

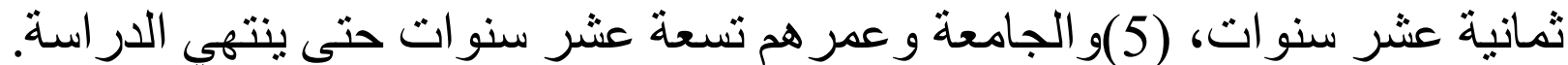

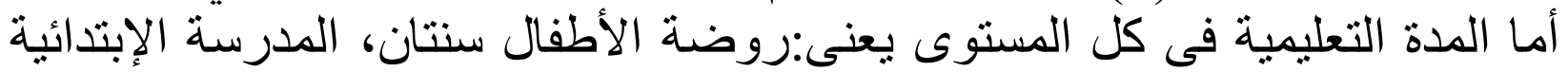

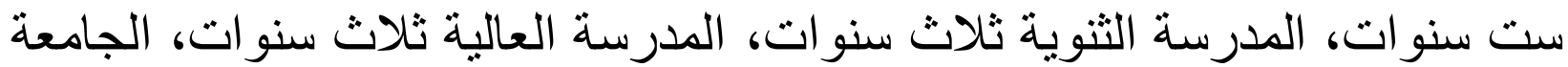

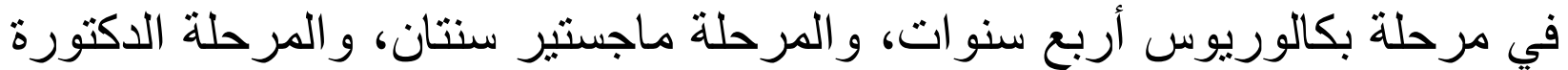

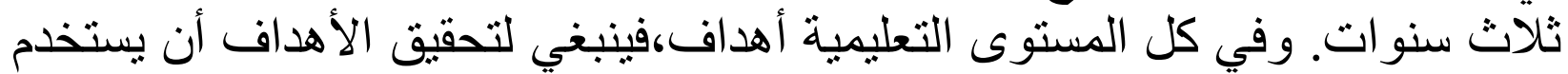

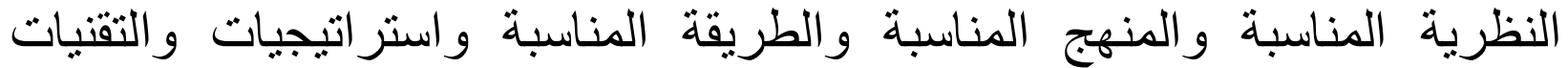
المناسبة على قدر قبول المتعلم في التعليم وفهم المادة العطية.

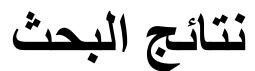

أما النتيجة من هذا البحث هي معرفة الظرية التعلمية المناسبة على مستوى التعليمية،

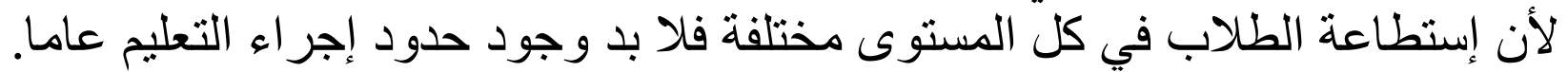

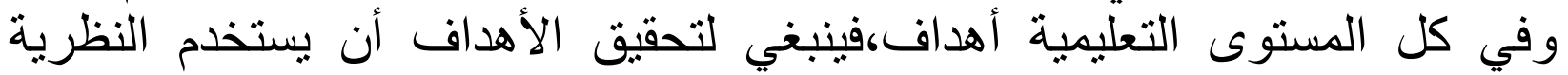

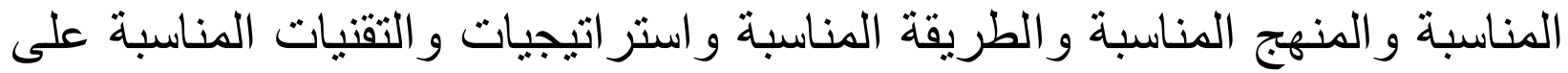

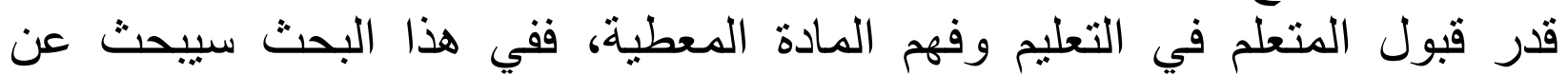

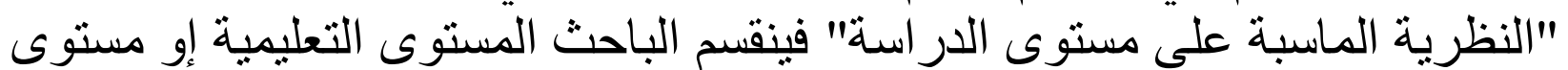

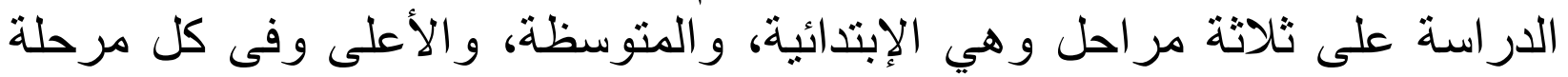
تتكون عل مر احل أيضا و هي الأدنى و الأوسط و الألعلى.

\begin{tabular}{|c|c|}
\hline أقسامها & مرحلة الدراسة \\
\hline الأدنى & مرحلة الإبتدائية \\
\hline الأوسط & \\
\hline و الأعلى & \\
\hline الأدنى & مرحلة المتوسطة \\
\hline
\end{tabular}

${ }^{8}$ Wikipidia.jenjang Pendidikan di Indonesia sesuai undang-Undang Pendidikan. 


\begin{tabular}{|c|c|}
\hline الأوسط & \\
\hline والأعلى & \multirow{4}{*}{ مرحلة الأعلى } \\
\hline الأدنى & \\
\hline الأوسط & \\
\hline و الأعلى & \\
\hline
\end{tabular}

1 1 ـ مرحلة الإبتدائية

و الطلاب فى مرحلة الإتدائية يعنى الطلاب فى روضى روضة الأطفال و الطلاب فى في

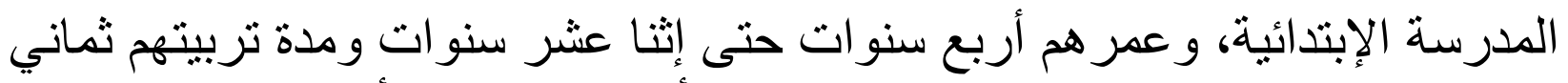

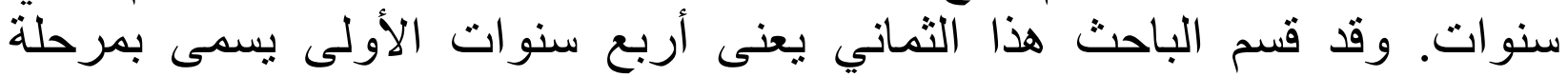

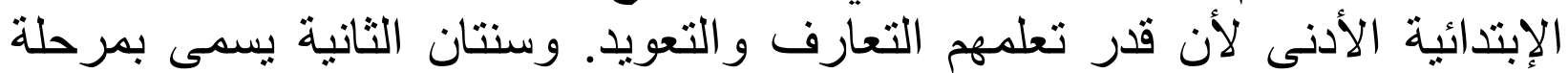

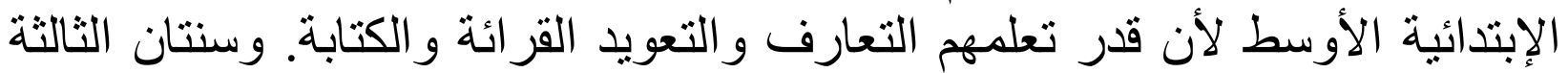

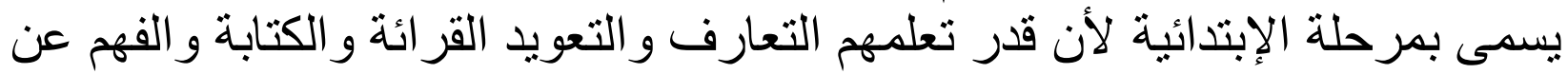

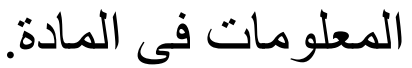
أ) خصائص النمو الحسي للطلاب بمرحلة الإبندائية:

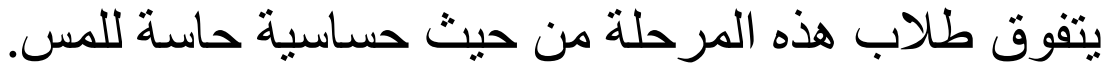

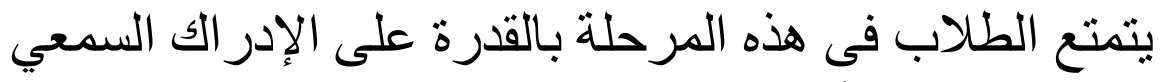

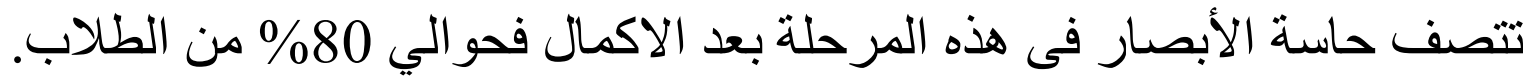

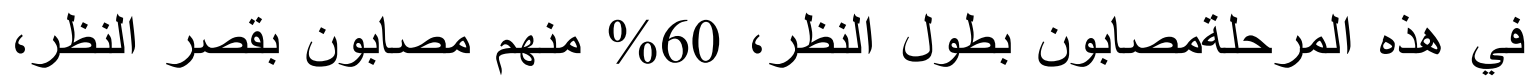
الذى تزداد نسبته بعد سن السابعة.

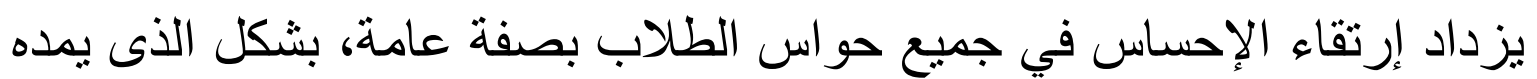

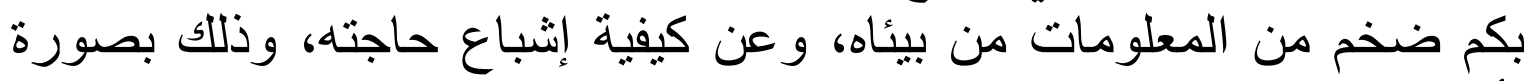

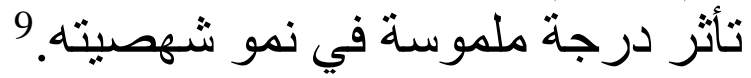
ب) خصائص النمو العقلي_الفكري للطلاب بمرحلة الإبتدائية:

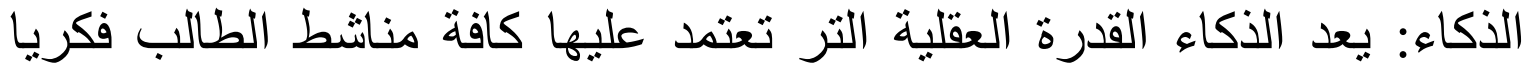

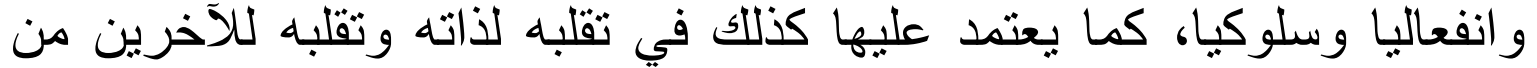

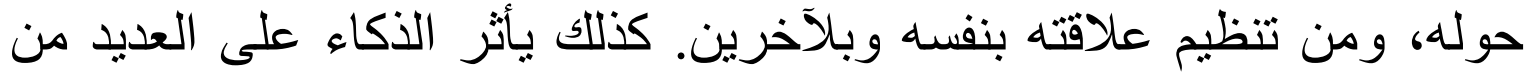

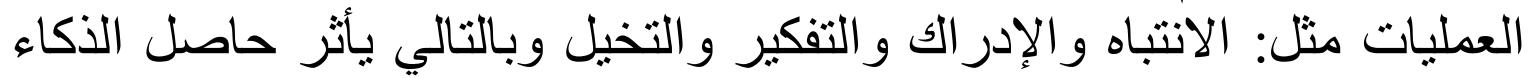

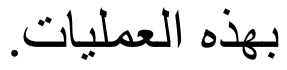
أما خصائص النمو العقلي_الفكري للطلاب بمرحلة الإبتدئية كما يلي:

خالد موسى, خصائص الطلاب في مرحلة الإبتدائية, المملكة العربية السعودية.2013 9 


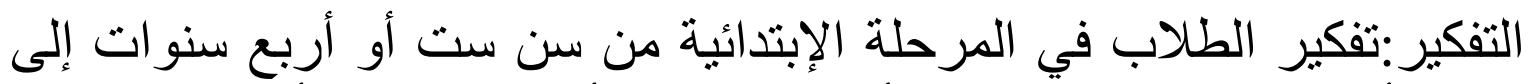

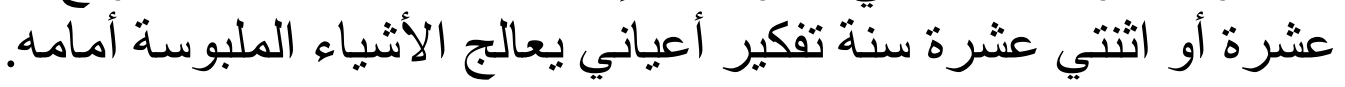

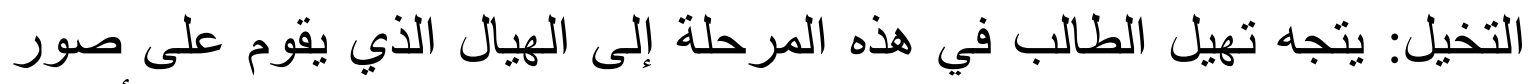

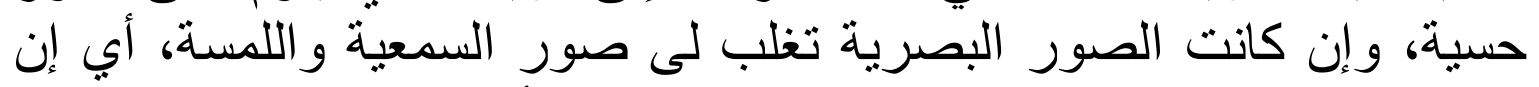
عملية التخيل لدى الطالب تتجه إلى ناحية بدلا من أن تحرره من قيود الزمان النمان

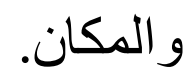

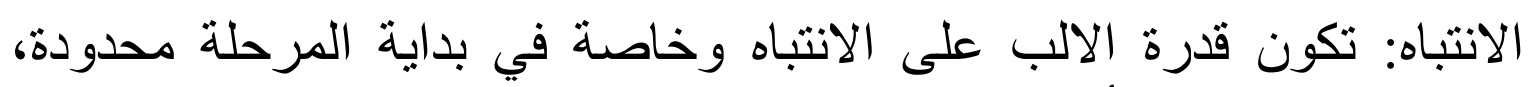

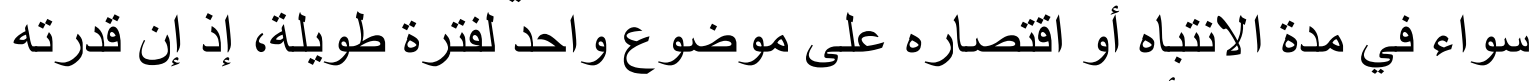

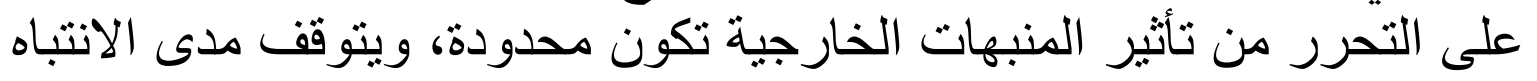

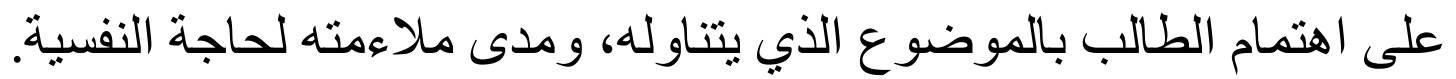

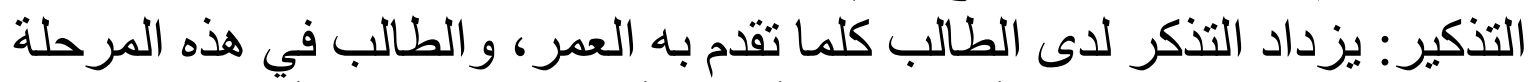

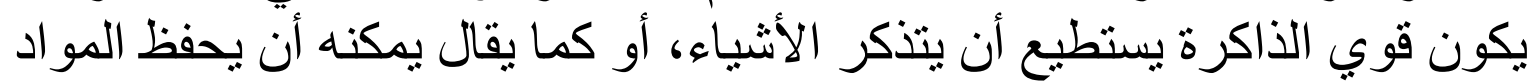

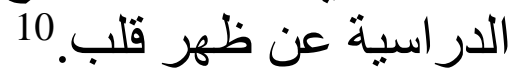

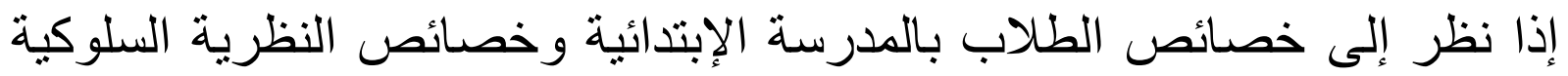

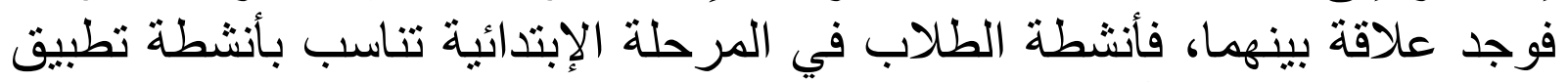

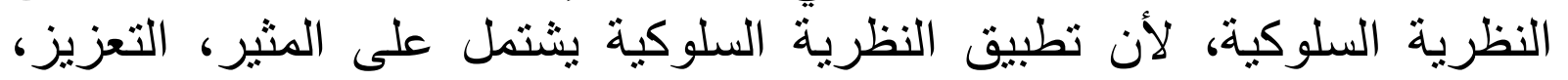
و العقاب، و هذا الثلاثة عملية لتعويد الطلاب بلابلة بلمادة المعطية. 2. مرحلة المتوسطة ولة فذابة و الطلاب فى مرحلة المتوسطة يعنى الطلاب فى المدرسة الثانوية و الطلاب فى الثى

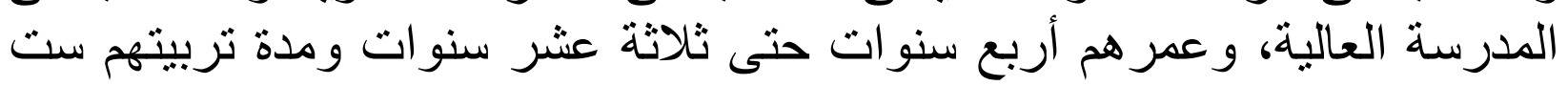

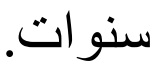
وقد قسم الباحث هذا الست يعنى سنتان الأولى يسمى بمرحلة المتوسطة الأدنى لأن

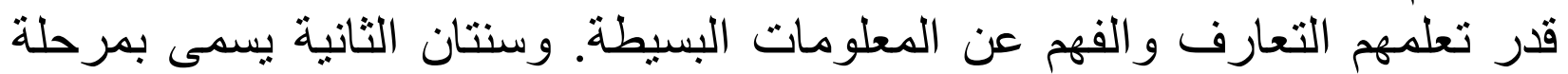

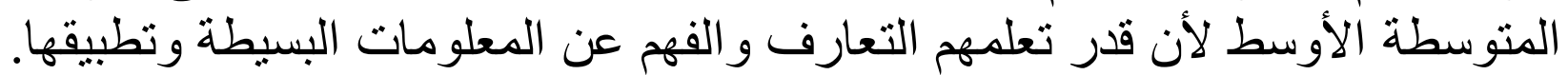

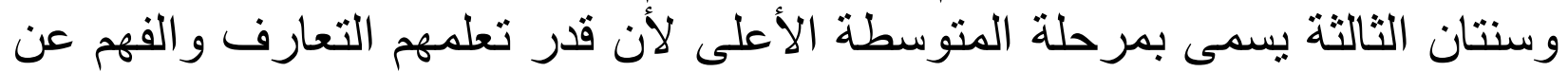

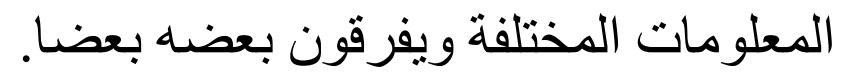
أما خصائص نمو الطلاب بمرحلة المتوسطة كما يلي: تثميز المرحلة المتوسطة

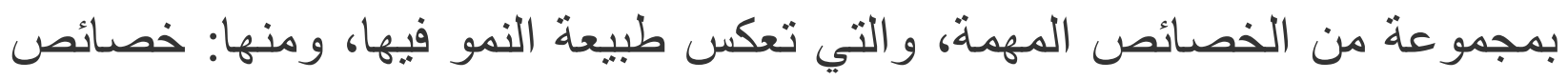

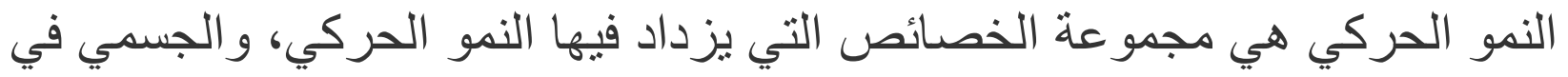

خالد موسى, خصائص الطلاب في مرحلة الإبتدائية, المملكة العربية السعودية.2013 10 
المرحلة المتوسطة، مما يؤدي إلى تأثر الجسم بعوامل النمو المتطور، ومن أهمها:

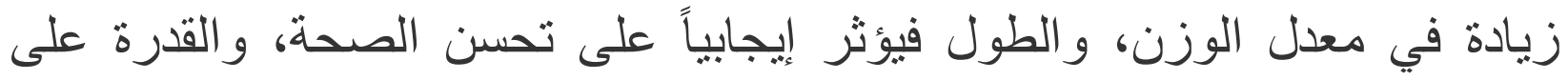

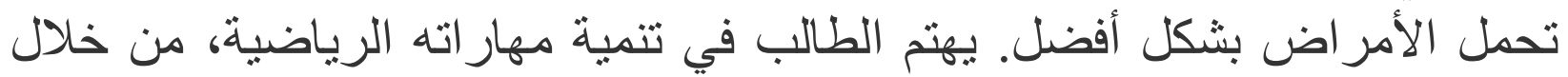

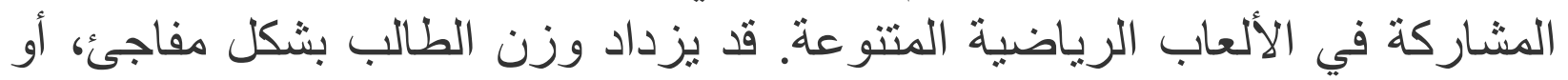

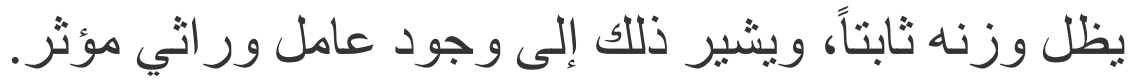
خصائص النمو الانفعالي هي مجموعة الخصائص التي تؤثر على الحالة الانفعالية

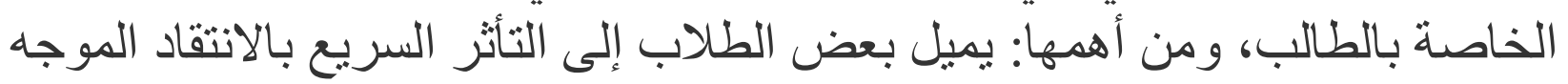

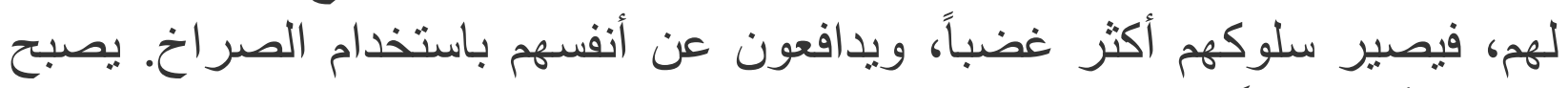

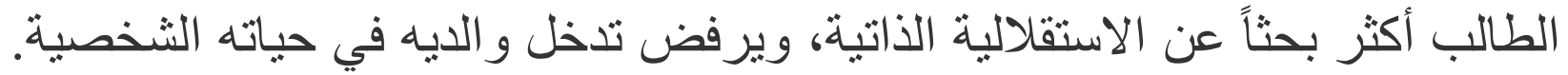

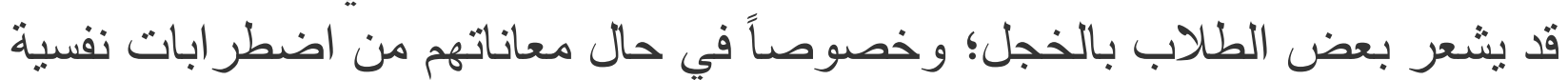

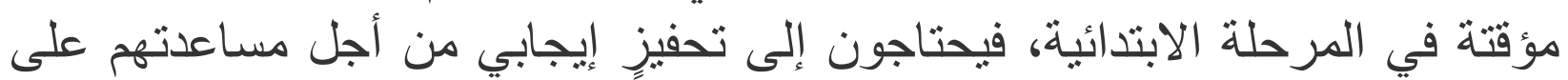

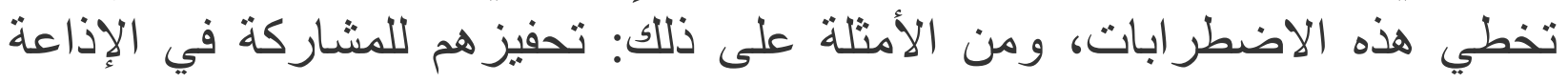

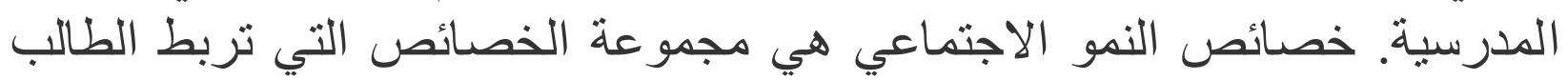

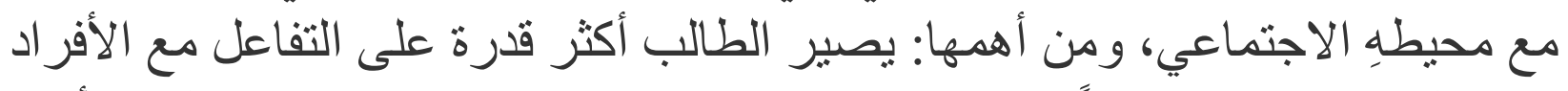

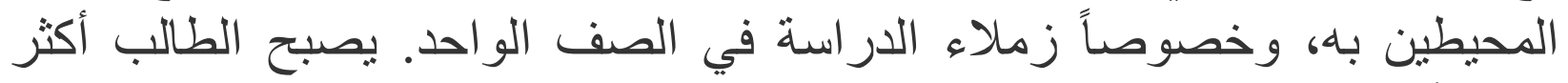

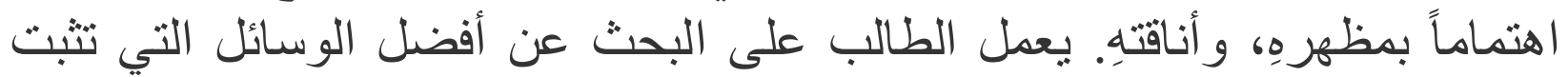

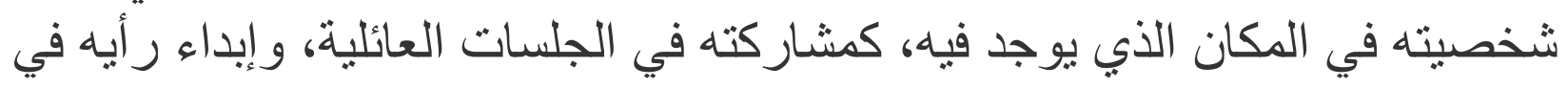

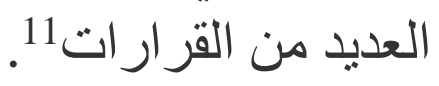

فالنظرية المناسبة لهذه المرحلة هي النظرية البنائية لأن النظرية البنائية يينى على النى

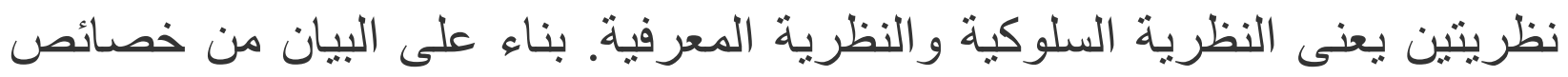
الطلاب بمرحلة المنوسطة وخصائص عملية التعليمة عند النظرية النية البنائية فوجد البناء العملية التعليمية في هذه المرحلة هي العملية لبناء سلوك الطية الطلاب ومعرفة الطلاب.

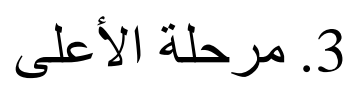

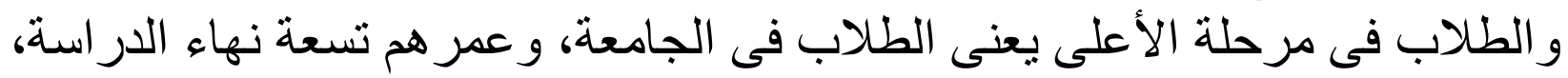

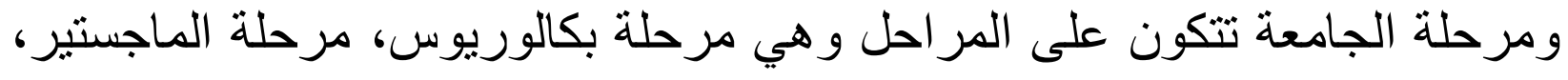


و مرحلة الدكتورة ومدة تربيتهم عامة فى مرحلة بكالوريوس أربع سنوات، وفى وفى

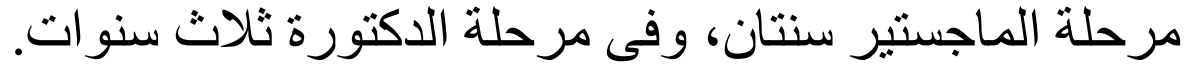

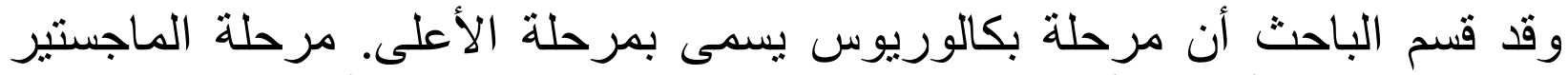

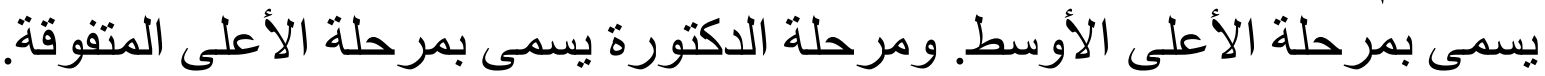

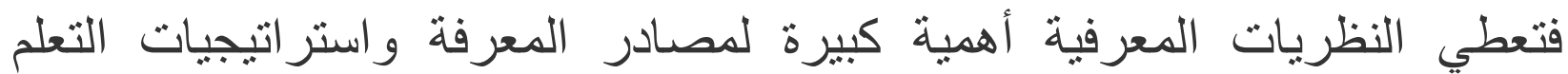

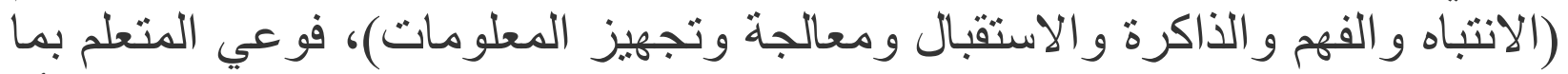

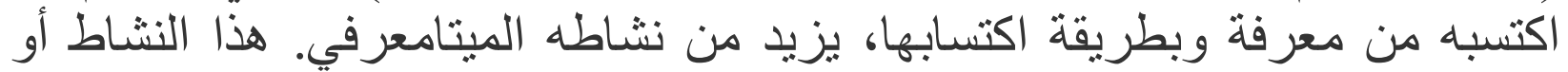

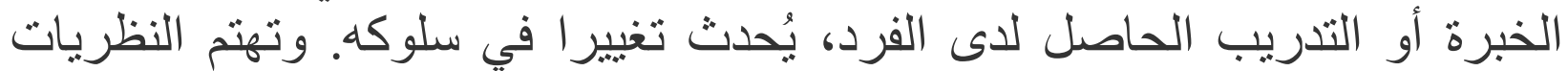

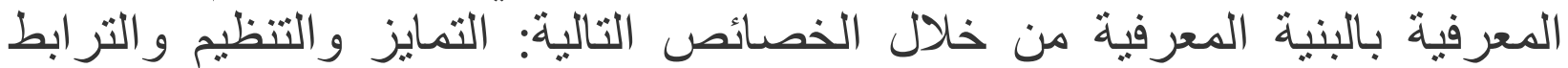

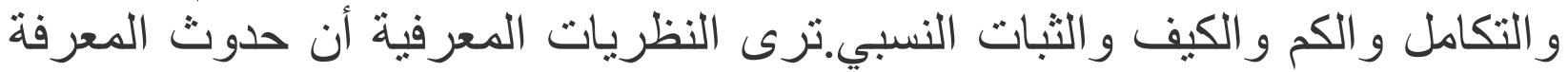

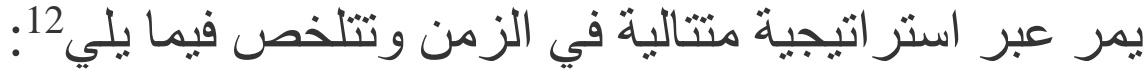

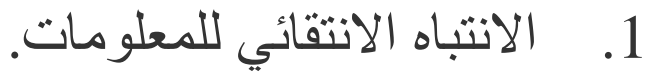

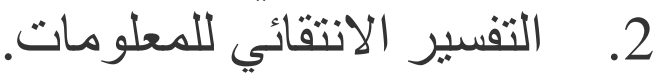

3. إعادة صياغة المعلومات، وبناء لمعاء معرفة جديدة. 4. الاحتفاظ بالمعلومات أو المعرفة المعاء المحصلة بالذاكرة. 5. استرجاع المعلومات عند الحاجة إليها.

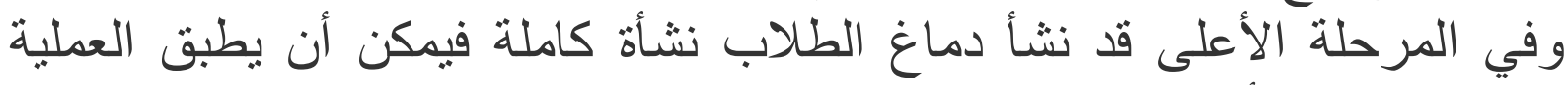

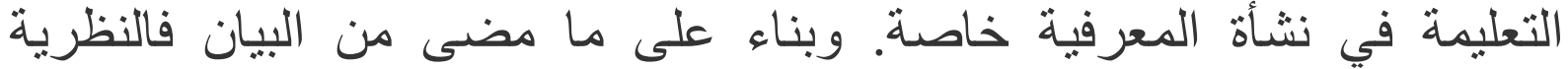

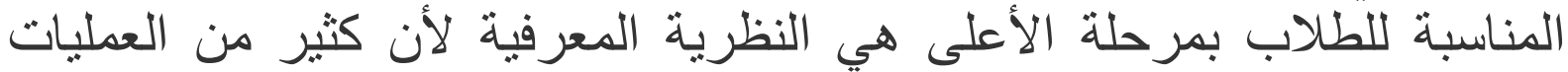

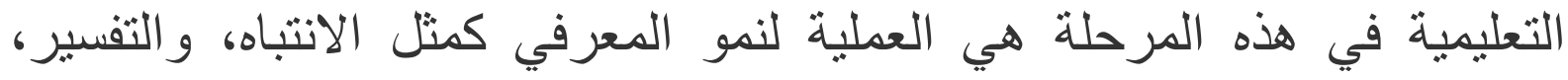
و التركيب، و التخزين ز التذكر ، و الاسترجاع عن العطة المعادة المعطية.

ما-هي-النظرية_المعرفية-؟-_https://www.new-educ.com 


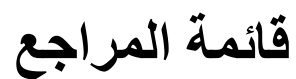

خالد موسى, 2013، خصائص الطلاب في مرحلة الإبتدائبة المملكة العربية السعودية.

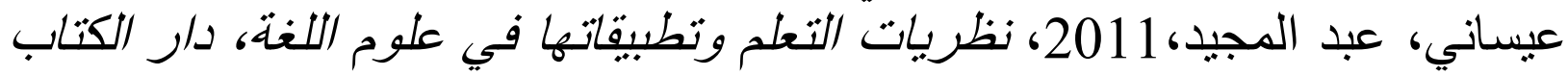

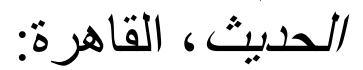

عبد ساجر ،كريم خلف الثمري, 2013، عو امل التفوق الدراسي لدى طلبة المرحلة الثانوية، مجلة كلية التربية للبنات التيري،

صلاح عبد الحجيد العربي، 1981، تعلم اللغات الحية وتعلبيها بين النظرية والتطبيق، الطبعة

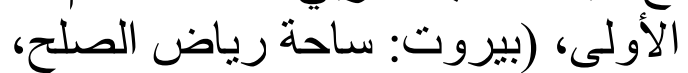

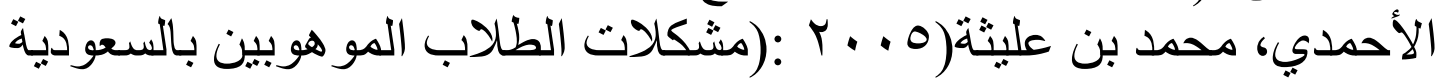

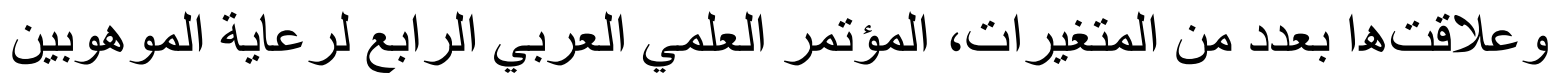

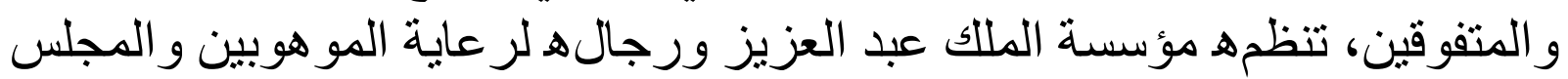

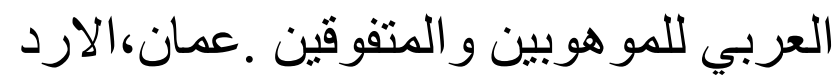

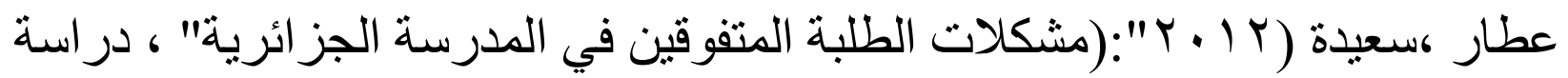

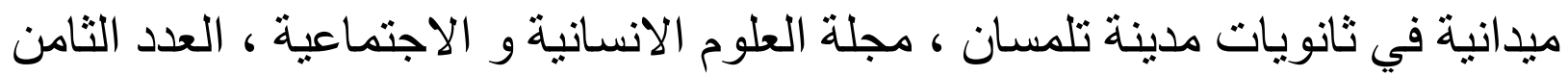

Moh. Ainin, Metodologi Penelitian Peningkatan Kualitas Pembelajaran Bahasa Arab; Teori Dan Praktek, (Malang: Bintang sejahtera, 2014)

Wikipidia.jenjang Pendidikan di Indonesia sesuai undang-Undang Pendidikan.

Features of the Educational Process", www.nubip.edu.ua,Retrieved 5-10-2018. Edited

، ألّع عليه بتاريخ

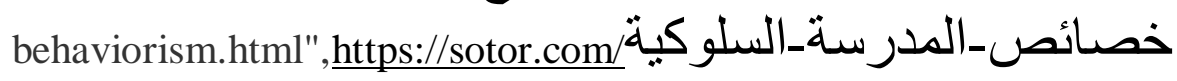

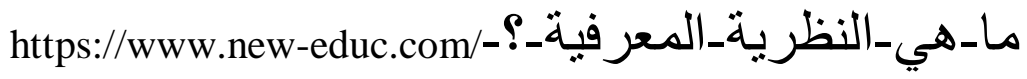

